\section{Ethics, a critical friend of research}

Ethics is perceived by some at least, as an opponent of research, or as a barrier or even a hindrance. Ethicists and researchers seem to be in two different camps or at different wavelengths. Are ethics and research really two competing rivals?

In my opinion, they are not. However, why is it perceived so at least by some?

There are many reasons. Historically, research started first and ethics followed. The new bioethics is not even 50 years old ${ }^{1}$. Secondly, ethics arose as a result of unethical conduct by some of the medical researchers who exploited and continue to exploit the vulnerable for easy and cheap research ${ }^{2,3,4}$. When one start studying the history how the researchers and research has been used or more correctly abused by some to establish power, authority and domination, it become clear why this hostile feelings had been generated ${ }^{5}$. Therefore, the field of ethics most probably attracted those who were not active in the field of research but in the field of humanities; human rights, philosophy, sociology law etc. These 'outsiders' of research enterprise probably felt they did not believe that justice could be expected from peer groups of researchers; the 'insiders'.

Research is expected to bring benefits to the humankind by generating new knowledge. Ethics propose to safeguard the rights of the participants and prevent potential physical and psychological harm that can be caused by research ${ }^{6}$. Hence, both groups have good intentions for the benefit of humankind. But why do they appear to be rivals?

Looking from this model; ethics as a friend of research, I believe researchers will be in a strong position to promote and safeguard ethical standards, if they are really convinced and committed to adhere to higher ethical safeguards and standards. This is because they know best about their piece of research and the methodology they follow. Therefore, if they look at their research question and the methodology, taking into consideration ethics as a part of research design and thereby incorporating higher ethical standards and safeguards within it, they will be able to elevate the quality of the research.

However, as it stands, researchers may be experts in research methodology and their subject, but may not be much familiar with the broader ethical issues. On the contrary, ethicists are experts in the subject but may not necessarily have expertise in research methodology on the specific research area of inquiry which they review. Considering that ethics committees review research in many different disciplines, they cannot be expected to be experts in all these different fields. Therefore, it is the duty and responsibility of the researcher himself to assist the ethicist by identifying specific ethical issues in his own research and propose proactive measures to deal with them.

Should the situation be left to continue as it is or is it not better to reshape the minds of the researchers to view ethics as an essential component of research? Such an approach will empower them to look at the ethical issue inherent in their proposal so that they can address these in advance, not because there is someone out there to get them, but only because one believes in high quality ethical research which will in turn strengthen their own proposal. This model will be a mutual catalyst for both research and ethics. However, there are challenges and barriers to get over if such a model is to succeed.

I have deliberately written this piece, wearing my hat as a clinician, based on medical research ethics. But I would like to reiterate that not only for medical research, ethics is an uncompromising discipline linked even to basic science research.

Ethics is all about relationships. As relationships involve consideration of power, there is an intimate link between ethics and power. In turn as knowledge creates power, one has to be mindful of potentials that knowledge creation could be associated with injustice.

Therefore, all knowledge creators should be fully aware of their moral obligations to strictly adhere to fundamental ethical values associated with science and research. Ethics of science spans across much broader than what is perceived as 'ethics' in its narrowest definition. Beyond any doubt let me reassure you that ethics is a critical friend of research.

\section{Athula Sumathipala \\ Keele University, UK \\ Email:a.sumathipala@keele.ac.uk}

\section{References}

Benatar S R, Daar A, Singer PA. (2003) Global health ethics: the rationale for mutual caring.

International Affairs. 79: 107-138.

Judgment of the Nuremberg International Military Tribunal 1946 (1947) 41 AJIL 172

Hawkins J, Emanuel EJ. Exploitation and Developing countries: The ethics of clinical research. Princeton University Press; 2000

Pogge T. Testing our drugs on the poor abroad, Exploitation and Developing countries: The ethics of clinical research. Princeton University Press; 2008; 106.

Benatar S. Justice and medical research. A global perspective. Bioethics. 2001; 15(4): 335-340

The Declaration of Helsinki 1964 and latest revision 2008 http://www.wma.net/en/30publications/10policies/b3/ 